\title{
Gridded data as a source of missing data replacement in station records
}

\author{
Jitendra Kumar Meher and Lalu Das*(0) \\ Department of Agricultural Meteorology and Physics, Bidhan Chandra Krishi Viswavidyalaya (BCKV), \\ Mohanpur, Nadia, West Bengal 741 252, India. \\ *Corresponding author. e-mail: daslalu@yahoo.co.in
}

MS received 25 July 2017; revised 4 June 2018; accepted 15 June 2018; published online 25 February 2019

The quality of available station data over western Himalayan region (WHR) of India is poor due to missing values, and hence quantifying climate change information at the station level is more challenging. The present study investigated the extent to which the available two different resolutions gridded rainfall data from the India Meteorological Department (IMD) namely, IMD- $0.25^{\circ} \times 0.25^{\circ}$ (IMD.25) and IMD $-1^{\circ} \times 1^{\circ}$ (IMD1) and global observational gridded data from the Climate Research Unit $\left(\mathrm{CRU}-0.5^{\circ} \times 0.5^{\circ}\right)$ of UK can be used as a substitute to replace the missing values in IMD station data. Long-term time series produced at each station location showed that IMD.25 data was much closer to observation both in magnitude and patterns compared to CRU and IMD1. The seasonal and annual scale performance of these gridded data has been evaluated through different agreement and error indices. The agreement indices showed higher values in case of IMD.25 data while IMD1 and CRU indicated poor results. Similarly, the estimated errors are minimum in IMD.25 and maximum in CRU data. Finally, an overall agreement index (OAI) was developed by the combined influence of all the agreement indices. The results of OAI for each station revealed that in more than $77 \%$ of cases, the performance of IMD.25 gridded data to reproduce station level rainfall is superior as compared to IMD1 $(<63 \%)$ and CRU $(<46 \%)$ data. Therefore, it is concluded that the IMD.25 gridded data may be reliably used as a substitute data source in place of missing rain-gauge data over the WHR.

Keywords. Rain gauge; missing data; western Himalaya; India Meteorological Department; Climate Research Unit.

\section{Introduction}

The Himalayan region has the largest area under the glacier $(70 \%$ of the non-polar glacier) and permafrost outside polar caps (Bothale et al. 2015; Mir et al. 2015). The rainfall over this region is highly influenced by the unique direction of the Indian monsoon from June to September and western disturbances from December to March (Dimri
2012; Das et al. 2014; Meher et al. 2014, 2017a, b; Dimri et al. 2016). Orography, altitude, topography and lower tropospheric circulation patterns are the other factors which regulated the rainfall over this region (Rao 1997; Dimri 2012; Das et al. 2014; Meher et al. 2014, 2017a,b). It is a wellknown fact that hydro-meteorological parameter like rainfall varies in time and space inherently (Meher et al. 2015). In higher altitude and complex 
topographical regions, it is a challenging parameter to predict (Das et al. 2016; Meher et al. 2017a). Many hydrologic simulation studies depend heavily on the availability of good-quality precipitation estimates. High costs of establishment, maintenance and a shortage of well-trained workforce restrict the setting up ground-based measurement networks (rain gauges or weather radar) in many remote locations of the world and the developing countries. Hence, in these places, the accurate estimation of precipitation faces many difficulties (Yilmaz and Hogue 2005). This situation imposes severe limitations on the possibility and reliability of many hydrological studies, natural hazards, and early warning systems in these regions. For example, recent monsoon flooding in Uttarakhand (June-July 2013) caused massive damage not only to the property but also the population, and nearly 5700 people were presumed dead due to this devastating flood (Sahu 2014). So, there is a significant need for more research on Himalayan precipitation processes, as most studies have excluded the Himalayan region due to the region's complex topography and lack of adequate rain-gauge data (Shrestha 2000). The density of meteorological stations in the Himalaya region is less than elsewhere, and long-term data records are few even from the stations that do exist. Analysing the trends is also challenging. There are a few hill stations in India that have archival data going back a century or more but, for the most part, these data are either lost or have not been analysed. Most archival meteorological data in the region extends back to only 50 yr or less (Joshi and Negi 1995). To estimate long-term rainfall change and to develop downscaled future rainfall time series at the station level, a consistent data record is essential. However, in the western Himalayan region (WHR) availability of long-term station records and their consistency and quality of data are not adequate for analysis. Replacement of missing data could lead to a new approach in local climate studies; Joshi and Ganju (2010) used spatial interpolation technique to estimate the missing records of winter temperature and precipitation at different stations over the western Himalaya by using similar parameters of the neighbouring regions. Castaneda and Gonzalez (2008) found improved partial trends in the Patagonian precipitation by replacing the missing rain-gauge data for Argentinean Patagonian region with the help of gridded precipitation datasets from Delaware University. A correlation-based study was performed by Xie and Arkin (1995) for the intercomparison of gauge observations and satellite estimates of gridded monthly precipitations over $60^{\circ} \mathrm{N}$ to $60^{\circ} \mathrm{S}$ and found the gridded datasets are in good agreement with the gauge observation. A similar type of study as discussed in this paper has been reported by Yilmaz and Hogue (2005) in the form of intercomparison of different gridded data with the seven rain gauges located over the southeastern United States.

To study the climate change information over local places, generally, climatic records in monthly scale are used. Monthly rainfall estimates are generated from the daily rainfall measurement. Hence, the missing data primarily occurs in the daily data. The presence of missing values in monthly data indicates the absence of meteorological record for at least a 30 days period consecutively. Meher et al. (2017a, b) have mentioned different techniques for the substitution of missing data. Missing data substitution methods for rainfall are sensitive to the magnitude of the data estimates, outliers present in the data and seasonal variation of the data (Meher et al. 2017a), and hence, both daily and monthly data needs different techniques for the missing data substitution. Meher et al. (2017a) used three different methods, namely, (i) the k-nearest neighbour (Junninen et al. 2004; Dominick et al. 2012; Azid et al. 2013), (ii) Markov chain Monte Carlo multiple imputations (Geyer and Thompson 1992, 1995; Geyer 1994, 1999) method and (iii) the method of interpolation from the India Meteorological Department (IMD).25 gridded data developed by Pai et al. (2014) for substituting missing monthly rainfall data over the WHR. Similarly, Das et al. (2017) also highlighted the use of two different techniques namely the bias-corrected IMD-gridded data and multiple imputation chained equation to replace the missing temperature in the station record over the Himalayan region. In the case of rainfall, interpolation from the IMD.25 gridded data can be used as an effective technique to substitute missing data in the rain-gauge data (Meher et al. 2017b). The investigation by Meher et al. (2017a) did not include another potential source of IMD rainfall data, i.e., IMD1 gridded data developed by Rajeevan et al. (2008) and global observational data from Climate Research Unit (CRU). To meet this research gap, the present study extended the work through the inclusion of another version of gridded data from IMD, i.e., IMD1 and CRU. 


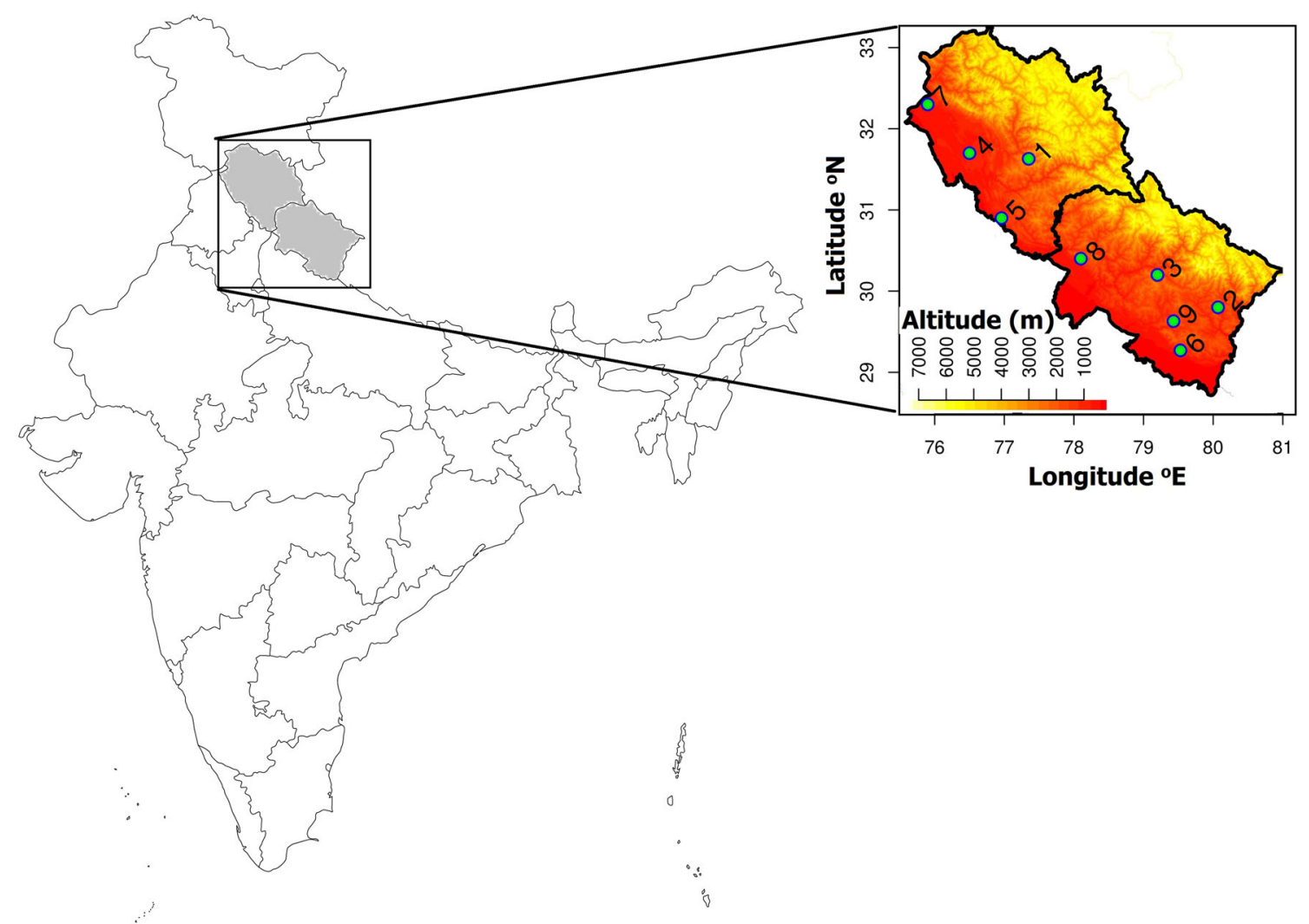

Figure 1. The left panel of the figure shows the subdivision map of India. Topography map of the two subdivisions of India namely Uttarakhand and Himachal Pradesh are shown in the right panel. The distributions of the nine rain-gauge stations taken in this study are shown by small circles with serial ID (see table 1 for station names and serial ID).

Monthly rainfall data provided by IMD for the WHR contains numerous missing values in different years of the entire analysis period. One of the siginificant challenges for the scientific community is to deal with those missing values and provide useful climate change information at local scale. Hence, the present work has been designed to meet two major objectives as follows:

1. To replace the missing values in the station rainfall data using some standard and recognised gridded data sources.

2. To judge the skills of gridded data to reproduce station data at the missing location using different agreement and error indices.

Section 2 of the paper describes the data and methods used for the present work. The first objective was a technical approach to the work; hence, this has been discussed in the methodology section. The major findings of the second objective were discussed in section 3, while the concluding remarks were highlighted in section 4 .

\section{Materials and methods}

\subsection{Study region}

Indian WHR is located at $73^{\circ} 8^{\prime}-81^{\circ} 1^{\prime} \mathrm{E}$ longitude and $28^{\circ} 7^{\prime}-35^{\circ} 4^{\prime} \mathrm{N}$ latitude, as shown in figure 1 . The total catchment area of the basin is $3,29,397 \mathrm{~km}^{2}$ with an elevation range of 200-8000 m above mean sea level. WHR stretches from the Kashmir valley to the hills of Uttaranchal through the state of Himachal Pradesh. There are two different types of agro-climatic zones over this region. First one is the high altitude temperate (humid to cold arid, total annual rainfall $<1200 \mathrm{~mm}$ ) areas of Jammu and Kashmir. The second one is the hill temperate (perhumid to subhumid, total annual rainfall 1200-1800 mm) region of Himachal Pradesh and Uttarakhand. This region forms the watershed portion of the river Indus, its five tributaries and the main Ganga river.

\subsection{Observed rain-gauge data and quality test}

Monthly rainfall data from rain-gauge stations located over the WHR was provided by the IMD, 
Table 1. Description of the rain-gauge stations taken in this study with their geographical location over the WHR.

\begin{tabular}{llccr}
\hline Station & Abr. & Lon. & Lat. & $\% \mathrm{MD}$ \\
\hline 1. Banjar & BAN & $77^{\circ} 35^{\prime}$ & $31^{\circ} 63^{\prime}$ & 13.8 \\
2. Berinag & BER & $80^{\circ} 07^{\prime}$ & $29^{\circ} 80^{\prime}$ & 26.1 \\
3. Bironkhol & BIR & $79^{\circ} 20^{\prime}$ & $30^{\circ} 20^{\prime}$ & 17.9 \\
4. Hamirpur & HAM & $76^{\circ} 50^{\prime}$ & $31^{\circ} 70^{\prime}$ & 9.6 \\
5. Kasauli & KAS & $76^{\circ} 96^{\prime}$ & $30^{\circ} 90^{\prime}$ & 9.6 \\
6.Kathgodam & KAT & $79^{\circ} 53^{\prime}$ & $29^{\circ} 27^{\prime}$ & 29.2 \\
7.Nurpur & NUR & $75^{\circ} 90^{\prime}$ & $32^{\circ} 30^{\prime}$ & 9.7 \\
8.Rajpur & RAJ & $78^{\circ} 10^{\prime}$ & $30^{\circ} 40^{\prime}$ & 24.6 \\
9.Ranikhet & RAN & $79^{\circ} 43^{\prime}$ & $29^{\circ} 63^{\prime}$ & 15.7
\end{tabular}

Abr.: abbreviation; Lat.: latitude; Lon.: longitude; \%MD: percentage of missing data.

Pune, India for the period of 1901-2010. A total of nine rain-gauge stations having $>70 \%$ of quality data during 1901-2004 were considered for the present study and stations having more than $30 \%$ missing values were not considered for this replacement procedures. The detailed description of the stations along with their abbreviations is discussed in table 1 and the distribution and location of the stations are shown in figure 1 . The good quality of record for a particular year indicates at least seven observations are available out of 12 months.

\subsection{Gridded data}

Gridded datasets are available from different sources at global, regional, and local scale. Some of them are reanalysis data based on model simulation, station data and sometime satellite-based remote sensing, and some of them are based on purely station records. These datasets are very much useful in climate change assessment studies where adequate station information is not available. As the gridded datasets are prepared from different sources of information, the performance of this datasets must be tested against the observational data. Upon visualising the superior performance of the gridded datasets, they may be used to substitute the missing records in the observational datasets. With this hypothesis, the present study was carried out using three different types of gridded datasets, viz., (i) high-resolution $\left(1^{\circ} \times 1^{\circ}\right)$ long period $(1901-$ 2004) daily data (IMD1) (Rajeevan et al. 2008), (ii) high spatial resolution $\left(0.25^{\circ} \times 0.25^{\circ}\right)$ long period (1901-2010) daily gridded rainfall dataset (IMD.25) over India (Pai et al. 2014) and (iii) CRU TS v. 3.21 high-resolution $\left(0.5^{\circ} \times 0.5^{\circ}\right)$ long period (1901-2012) gridded monthly precipitation datasets (CRU) downloaded from the http://badc. nerc.ac.uk/browse/badc/cru/data/cru_ts/cru_ts_3. 21/station/. Both IMD.25 and the IMD1 datasets were prepared by the National Climate Centre of IMD, Pune, India. CRU data was prepared by CRU and contains precipitation data for all the land area excluding Antarctica. This gridded data was prepared based on different numbers of stations as well different interpolation techniques. Other gridded data namely the reanalysis data was not considered as those data is mostly generated using some atmospheric models. Figure 2(a) displays the years in which the rain-gauge data has missing values. The complete observational dataset with substituted missing values from the IMD.25 gridded data is displayed in figure $2(\mathrm{~b})$.

\subsection{Methods}

\subsubsection{Interpolation of gridded data}

Gridded data for a particular climatic variable generally contains the estimates of that variable for a specific period, at each of the grid points or pixel. Bilinear interpolation technique has been used in this study to interpolate the gridded data at each of the station locations. This is a resampling technique which uses the distance-weighted mean of the four closest grid/pixel values to evaluate a new grid value (Plautikof et al. 1997; Das and Lohar 2005; Das et al. 2012; Chang 2013). The weights were applied based on the shortest distance of the four nearest grid centres smoothing the output raster grid. Interpolation is not recommended for daily precipitation. However, if the data is aggregated, e.g., monthly or seasonal mean values, then the bilinear interpolation is more appropriate because the data is smoother in space and the mean estimates are closer to being normally distributed (according to the central limiting theorem). Hence, in this study prior to performing the bilinear interpolation of the gridded data (which contains monthly rainfall estimates), we converted the monthly gridded data into its seasonal form. The interpolation was carried out using the 'ESD' package (Benestad et al. 2014), which runs under 'R-statistical software'.

\subsubsection{Substitution of missing values}

The method proposed by Meher et al. (2017a) has been followed for the substitution of missing values 
a

Original IMD station data

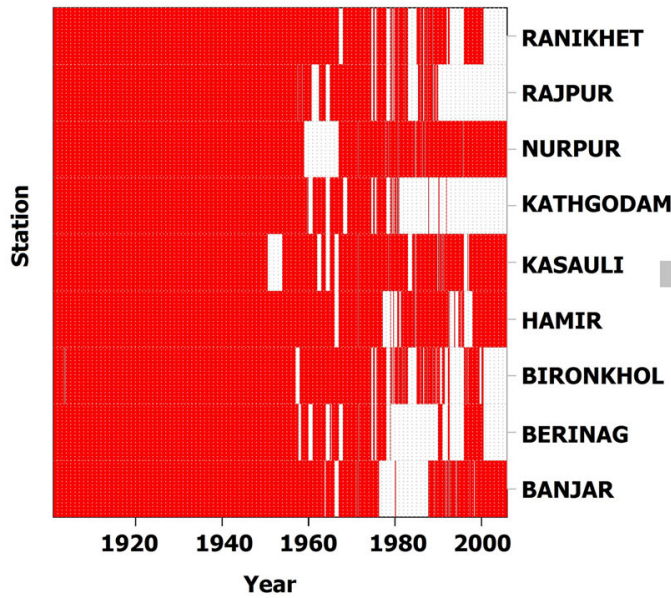

b

IMD data after substitution from IMD.25

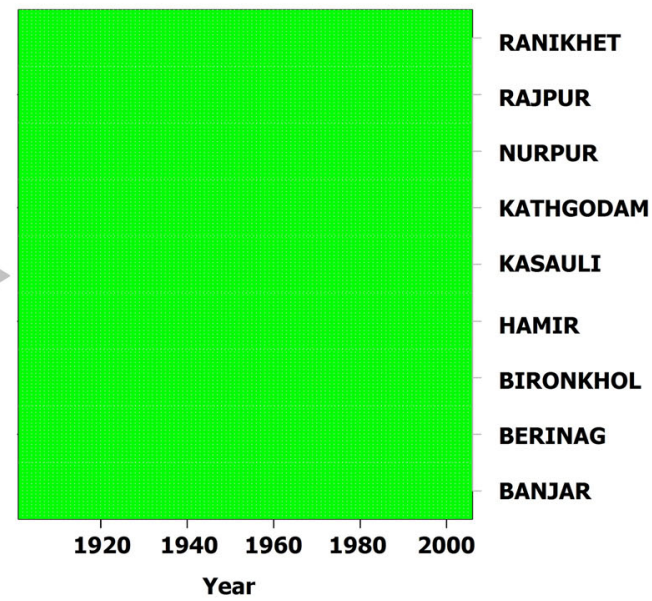

Figure 2. The left panel of the figure shows the summary of missing values in the original IMD data while the right panel shows the missing value substituted IMD station data from the IMD.25 gridded data.

in the station data. The stepwise procedure for substitution of missing values in the original observed station was as follows. Here, we have taken an example for a single station; a similar procedure has been applied to all the stations to get a complete dataset.

Step 1: Take the whole time series data $\left(X_{i}\right)$ of a particular station with missing values. Here, the value of ' $i$ ' varies from 1 to the length of the time series (here 1901-2004). Similarly, $X$ represents the rainfall estimates. For example, $X_{1}, X_{2}, X_{3}$, $X_{4},\langle\mathrm{NA}\rangle, X_{6}, X_{7},\langle\mathrm{NA}\rangle,\langle\mathrm{NA}\rangle, X_{10}, \ldots, X_{(i-3)}$, $\langle\mathrm{NA}\rangle, X_{i}$.

Step 2: Keep the new datasets $\left(X_{k}\right)$ by removing the missing values from $\left(X_{i}\right)$. For example, $X_{1}, X_{2}$, $X_{3}, X_{4}, X_{6}, X_{7}, X_{10}, \ldots, X_{(i-3)}, X_{k}$. Here, $X_{k}$ is the last non-missing value of the rainfall time series.

Step 3: Randomly remove some data (say 20\%) from $X_{k}$. For example, $X_{1},\langle\mathrm{NA}\rangle,\langle\mathrm{NA}\rangle, X_{4}, X_{6}$, $\langle\mathrm{NA}\rangle, X_{10}, \ldots, X_{(i-3)},\langle\mathrm{NA}\rangle$.

Step 4: Use the data of step 3 to fill the missing value through substitution from different gridded datasets.

Step 5: Compare the datasets generated in steps 2 and 4 through different agreement and error matrices. The gridded dataset which shows the minimum error value and maximum agreement value is most suitable for missing value replacement in the data used in step 1. As the computed data after missing value replacement contains some bias as compared to the original data without any missing values, mean bias (wet/dry) for each station was removed from the rain-gauge stations.

Step 6: Use the original data and repeat steps 4 and 5 .

Finally, those bias corrected station data generated in step 5 was considered as 'reference stations'.

\subsubsection{Statistical matrices}

The efficiency of all considered gridded data to reproduce the observed rainfall is evaluated through a comparison of the values of various statistical agreement indices and error indices, which are described below. The necessary expression for all the statistical indices used in this study is given in table 2. All the calculations are done using 'hydroGOF' package (Zambrano-Bigiarini 2014), which runs under 'R-statistical software'.

Nash-Sutcliffe efficiency (NSE): It is a normalised statistic that determines the relative magnitude of the residual variance ('noise') compared to the measured data variance ('information'). It has a range of $-\infty$ to 1 . Essentially, the closer to 1, the more accurate the grid data is. NSE is highly sensitive to high peaks. NSE $=1$ corresponds to a perfect match of the grid and observed data. $\mathrm{NSE}=0$ indicates that the grid data is as accurate as the mean of the observed data. And $-\infty<$ NSE $<0$ indicates that the observed mean is a better predictor than the model. Only positions with non-missing values in observation and grid data are considered in the computation of NSE. 
Table 2. Different statistical indices used in this study.

\begin{tabular}{lcc}
\hline Name of the statistics & Mathematical expression & References \\
\hline NSE & NSE $=1-\frac{\sum_{i=1}^{N}\left(G_{i}-O_{i}\right)^{2}}{\sum_{i=1}^{N}\left(O_{i}-\bar{O}\right)^{2}}$ & Nash and Sutcliffe (1970) \\
Correlation & $R=\frac{(1 / N) \sum_{i=1}^{N}\left(G_{i}-\bar{G}\right)\left(O_{i}-\bar{O}\right)}{\sigma_{G} \sigma_{O}}$ & Taylor (2001) \\
Index of agreement $(d$-index $)$ & $d=1.0-\left(\frac{\sum_{i=1}^{N}\left(O_{i}-G_{i}\right)^{2}}{\sum_{i=1}^{N}\left(\left|G_{i}-\bar{O}\right|+\left|O_{i}-\bar{O}\right|\right)^{2}}\right)$ & Willmott (1981) \\
Normalised total RMSE & NTRMSE $=\frac{1}{\sigma_{0}}\left[\frac{1}{N} \sum_{i=1}^{N}\left(G_{i}-O_{i}\right)^{2}\right]^{\frac{1}{2}}$ & Covey et al. (2002) \\
Normalised mean absolute error & NMAE $=\frac{1}{\sigma_{0}}\left[\frac{1}{N}\left\{\sum_{i=1}^{N}\left|G_{i}-O_{i}\right|\right\}\right]^{\frac{1}{2}}$ & Janssen and Heuberger (1995) \\
Normalised RMSE & NRMSE $=\frac{100}{\sigma_{0}}\left[\frac{1}{N} \sum_{i=1}^{N}\left(G_{i}-O_{i}\right)^{2}\right]$ & Zambrano-Bigiarini (2014)
\end{tabular}

$G$ : gridded data; $O$ : observed rain-gauge data, $\sigma_{G}, \sigma_{O}$ : standard deviation of gridded data and observed rain-gauge data, respectively; $\bar{G}, \bar{O}$ : mean of gridded data and observed rain-gauge data, respectively.

Correlation ( $R$ ): It indicates the strength and direction of a linear relationship between two variables. Here, we have used the Pearson method for finding the linear association between the gridded data and observed data. This method is robust and has been recommended if the data comes from a bivariate normal distribution. $R=1$ corresponds to a perfect increasing linear relationship between grid and observed data, $R=-1$ indicates a perfect decreasing linear relationship between grid and observed data and $R=0$ indicates that there is no linear relationship between the variables.

Index of agreement (d-index): This is a standardised measure of the degree of prediction error and varies between 0 and 1 . It is helpful in detecting the proportional and additive difference in the means and variance of observed and gridded data. It is overly sensitive to extreme values due to the squared differences (Legates and McCabe 1999). $d=1$ corresponds to a perfect match between the observed and gridded data and $d=0$ indicates no agreement at all.

Normalised total root mean squared error (NTRMSE): It is used to measure the difference between values shown by gridded data and the values observed from the rain-gauge data. The differences calculated are called residuals and the NTRMSE serves to aggregate them into a single measure of predictive power. This is independent of the dimensional form of two variables.

Normalised mean absolute error (NMAE): This is less sensitive to extreme values than NTRMSE. It avoids the physically artificial exponentiation that is an artifact of statistical-mathematical reasoning from which RMSE comes. Nonetheless, since NMAE and NTRMSE are similar measures, it is appropriate, in many cases, to report either or both indices (Wilmot 1982).

Normalised root mean squared error (NRMSE): NRMSE is a powerful measure of error when there exists a distinct difference between the observed data and the gridded data. Here, the normalisation was achieved using the observed dataset. The normalisation factor depends on the choice of the user, while common choices are the mean, standard deviation or the range of the measured data. A lower NRMSE value indicates less residual variance. NRMSE is scale-dependent and is sensitive to outliers.

\subsubsection{Overall agreement index (OAI)}

It is intuitive that the agreement indices for any station may show higher values for a particular season while it may show lower values for another season depending on the percentage of missing values present in the station. Hence, to remove any such bias in the selection of a best-gridded data for a particular station, an OAI was formulated which was independent of the season. This was an index calculated using all the three agreement indices, i.e., $R, d$-index and NSE. For a particular station, there is a single value of $R, d$ and NSE. The indices either lies between 0 and 1 (for $d$-index) or less than zero and one (for NSE and $R$ ). As the three values are independent of dimensionality, they can be summed up, so the maximum value of OAI 
will be the sum of $R+d+\mathrm{NSE}=3$ for a particular season. It will be 15 in the case of four seasons and the annual time scale. If the calculated value of NSE or $R$ is zero or $<0$ for any station that means there is no contribution of NSE to a final value of 15 . Hence, the maximum value of OAI for a particular gridded data means that data is most suitable for substitution of missing value in the observational data.

\section{Results and discussion}

\subsection{Comparison between deliberately removed data from observation and corresponding data from different gridded sources}

The results obtained from the comparison between the values that are deliberately/randomly removed from the observational data and the corresponding data from the different gridded datasets (step 5 of section 2.4.2) are displayed in figure 3. Each box in figure 3 was calculated using the statistical values obtained from all the nine stations for individual gridded datasets. Results showed that median value of the $R$ and $d$-index of IMD.25 $(R=0.93, d=0.95)$ was greater than IMD1 $(R=0.83, d=0.81)$ and $\mathrm{CRU}(R=0.71, d=0.79)$ datasets. Similarly, the median value of NRMSE for IMD. 25 (110.0) was less than the IMD1 (114.0) and CRU (127.0) datasets. The comparison of interquartile range (IQR = third quartile-first quartile) of $R$ values showed that $\mathrm{IQR}_{\mathrm{IMD} .25}<\mathrm{IQR}_{\mathrm{IMD} 1}<$ $\mathrm{IQR}_{\mathrm{CRU}}$. A similar pattern of variation of IQR was also found for the $d$-index. In the case of NRMSE, the $\mathrm{IQR}_{\mathrm{IMD} 1}<\mathrm{IQR}_{\mathrm{IMD} .25}<\mathrm{IQR}_{\mathrm{CRU}}$. Hence, the IMD. 25 gridded dataset showed minimum error value and maximum agreement value in all the cases and can be considered as the most suitable gridded data source for replacing the missing values in the observational data.

\subsection{Comparison of complete datasets after missing value substitution}

A question may arise, how the gridded data may be useful to replace missing values in the station data while gridded data is originated from the station data? The answer lies in the techniques of generating gridded data and numbers of the station used for such techniques. Gridding methods normally used station data from the vicinity of the target grid and finally gridded values for any grippoint showed continuous data in spite of having some missing data for some station record (panel 2 of figure 2). So, the gridded data is basically generated from the combined influence of station data. For the purpose of gap filling in the station data using gridded data, bilinear interpolation has been done which used four points, so the substituted station data include information that is influenced by areas beyond the individual station.

\subsubsection{Analysis of linear correlation between missing value substituted observation and different gridded data}

Figures 4-6 show the scatter plot between the missing values substituted observational data and different gridded data interpolated to each of the station locations for the annual, monsoon and winter rainfall, respectively. The linear correlation $(R)$ values obtained from the best fit line using a linear regression analysis shows they were higher for the IMD. 25 datasets and low for the CRU datasets. Mean values of the linear correlation for IMD.25
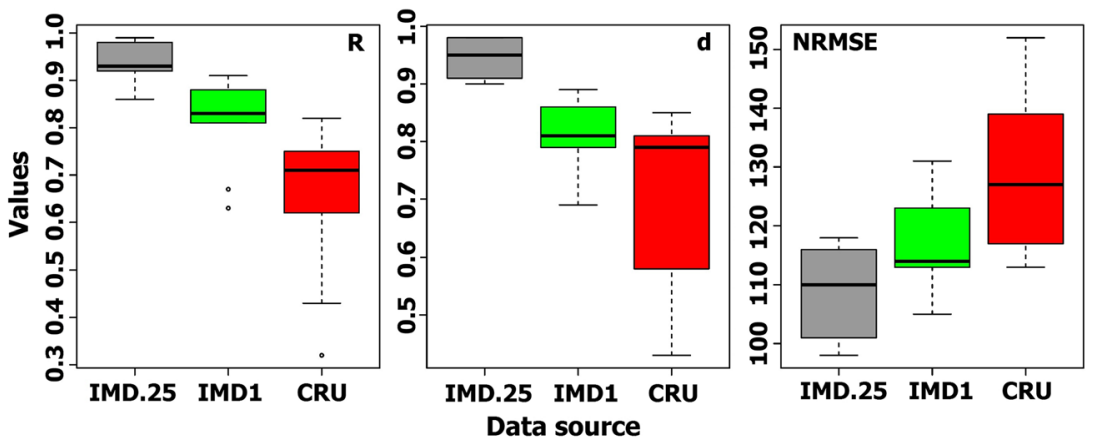

Figure 3. Comparison between the values that are deliberately/randomly removed from the observational data and the corresponding data from the different gridded datasets. Each box for the gridded datasets was calculated using the values of agreement and error indices calculated for all the nine stations. The indices were calculated using the monthly data provided by the IMD and the monthly data extracted from different gridded datasets during the period 1901-2004. 


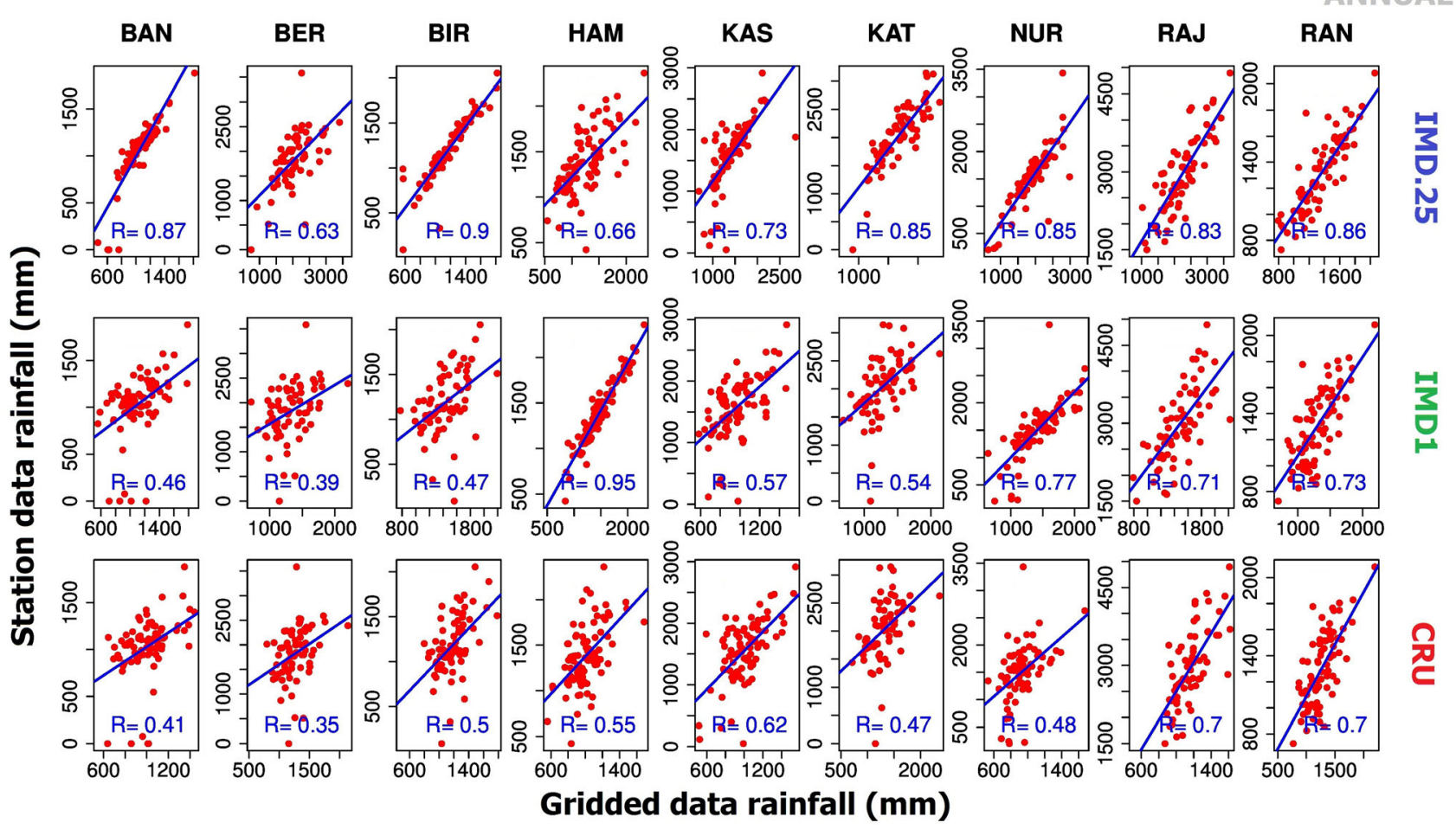

Figure 4. Scatter plot of annual rainfall between observation and different gridded datasets (IMD.25, IMD 1 and CRU) at each station location.

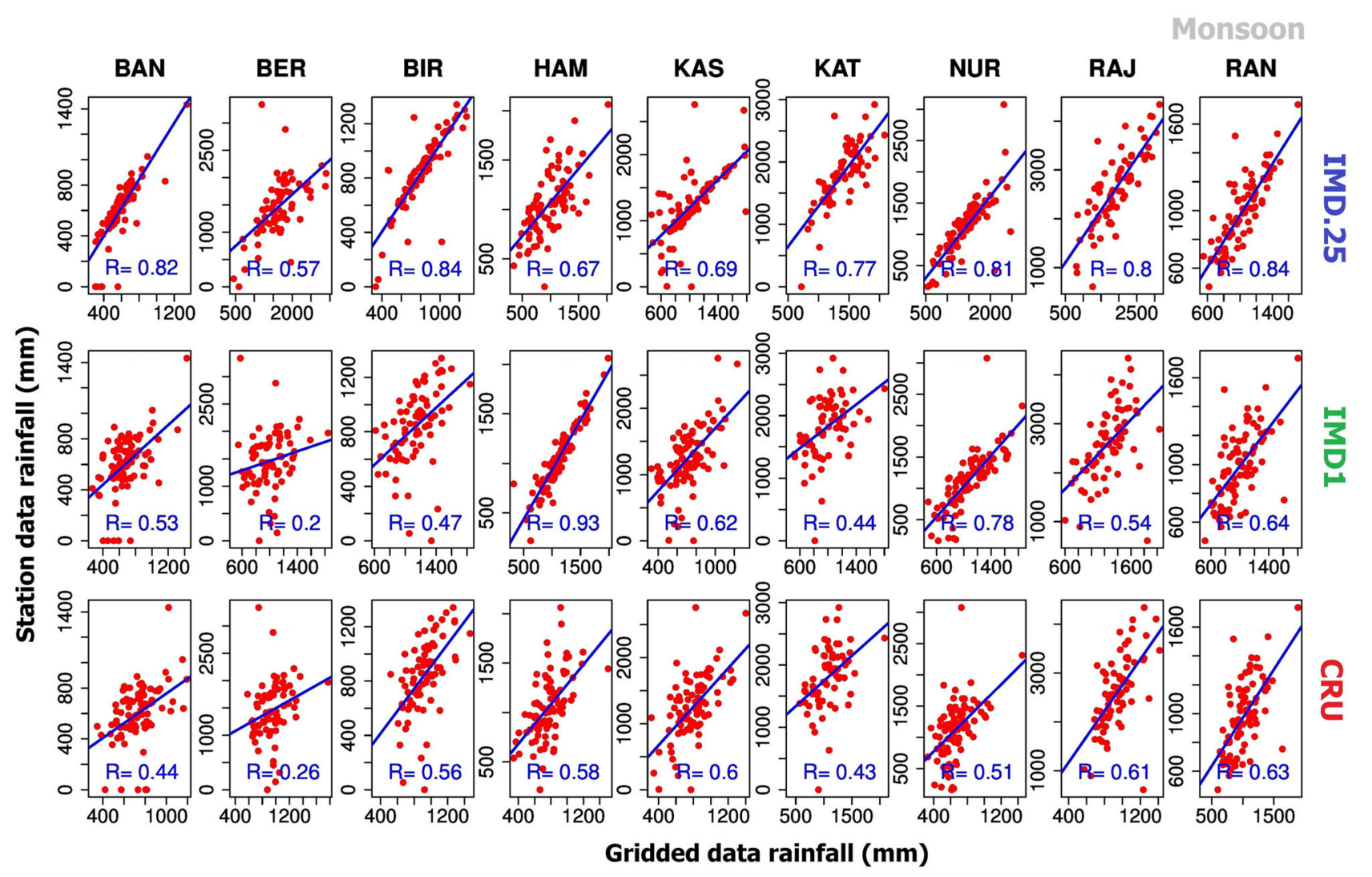

Figure 5. Scatter plot of total monsoon rainfall between observation and different gridded datasets (IMD.25, IMD 1 and $\mathrm{CRU})$ at each station location. 


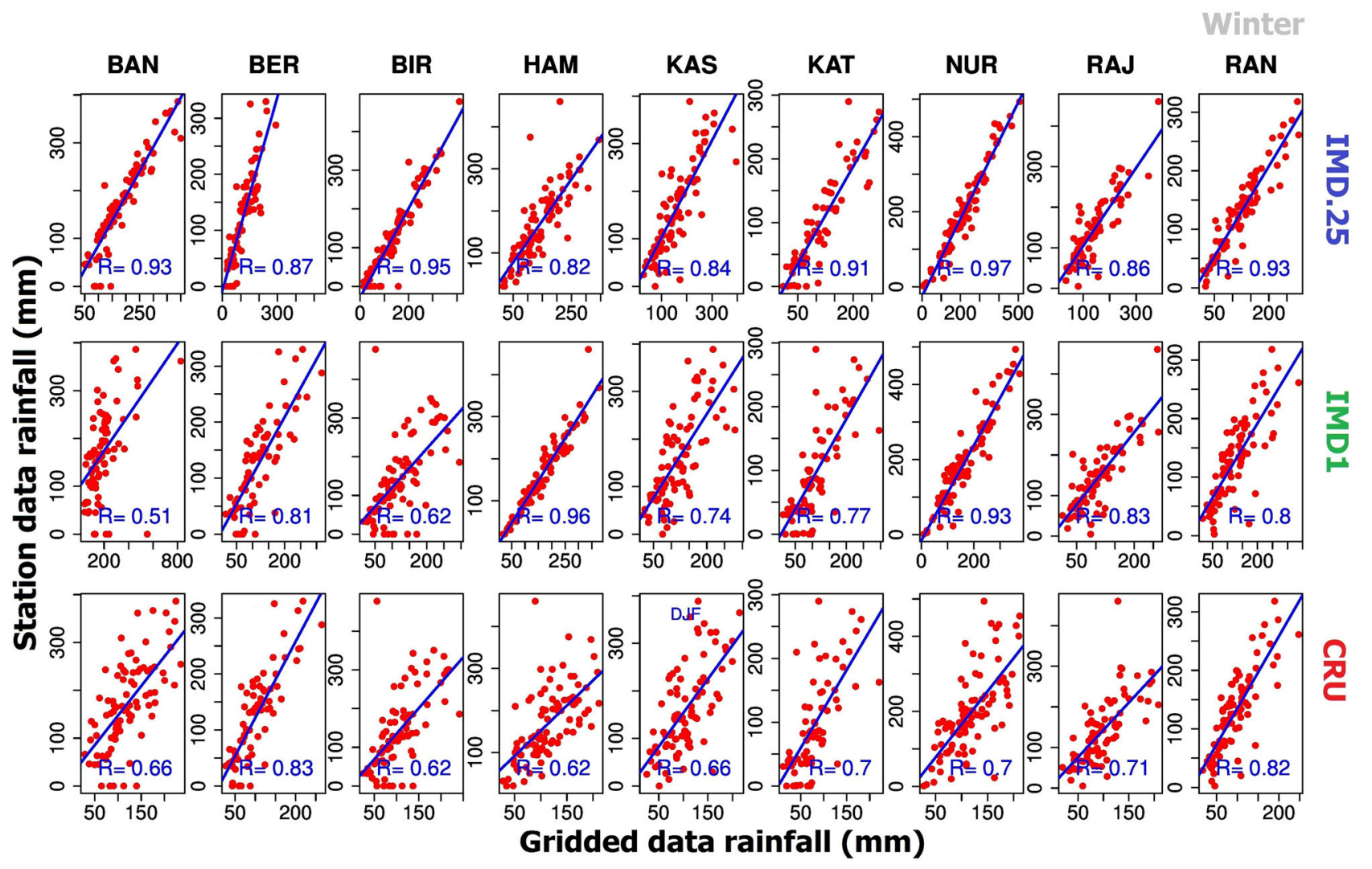

Figure 6. Scatter plot of total winter rainfall between observation and different gridded datasets (IMD.25, IMD1 and CRU) at each station location.

$\left(R_{\mathrm{IMD} .25}\right)$ were $0.80,0.76$ and 0.90 for annual, monsoon and winter rainfall, respectively. Similarly, calculated $R_{\mathrm{IMD} 1}$ of annual, monsoon and winter rainfall were $0.62,0.57$ and 0.77 , respectively. $R_{\mathrm{CRU}}$ values were lower than the $R_{\mathrm{IMD} 1}$ and $R_{\mathrm{IMD} .25}$, which shows that, for most of the stations, the mean value of this linear correlation for IMD.25 data were higher than the other two datasets (i.e., $\left.R_{\mathrm{IMD} .25}>R_{\mathrm{IMD} 1}>R_{\mathrm{CRU}}\right)$. The only station showing an exception to this result was Hamirpur. For Hamirpur, the $R_{\mathrm{IMD} 1}$ values were greater than the $R_{\mathrm{IMD} .25}$ and $R_{\mathrm{CRU}}$. It was also found that $R$ of winter rainfall was always higher than the monsoon and annual rainfall. The reason for such a high correlation during winter rainfall was missing values in December to February months were less as compared to other months.

Different statistical indices used in this study are sensitive to magnitudes of both gridded and observed data, because some indices are sensitive to the outlier, extreme values while others are sensitive to the mean values. Therefore, we obtained a different response to different indices using the same data series during computation. Several agreements and error indices calculated for each interpolated rain-gauge stations are summarised in tables 3 and 4 and detailed discussion is inscribed as follows.

\subsubsection{Analysis of agreement indices}

Values of different agreement indices ( $d$-index, $R$ and NSE) calculated from the time series of missing value replaced station data and different gridded dataset for the different season were inscribed in table 3 . The mean values of $d$-index, $R$ and NSE of IMD.25 data for annual, monsoon, postmonsoon, pre-monsoon and winter were $(0.81,0.80$ and 0.30$),(0.79,0.76$ and 0.25$),(0.97,0.95$ and $0.89),(0.90,0.85$ and 0.67$)$ and $(0.94,0.90$ and $0.80)$, respectively. Similarly, for IMD1 data they were calculated as $(0.65,0.62$ and -0.74$),(0.64$, 0.57 and -0.80$),(0.92,0.88$ and 0.73$),(0.78,0.72$ and 0.43$),(0.84,0.77$ and 0.45$)$, respectively. It was found that the calculated values of all the agreement indices were higher for IMD.25 data, whereas they were low for CRU data. The calculated values of NSE for IMD.25 data were positive for the majority of the stations in all the seasons, whereas for IMD1 and CRU data, they were 
Table 3. Values of different agreement indices calculated for different gridded datasets for different seasons and annual time scale.

\begin{tabular}{|c|c|c|c|c|c|c|c|c|c|c|c|c|c|c|c|}
\hline \multirow{2}{*}{$\begin{array}{l}\text { Interpolated } \\
\text { stations }\end{array}$} & \multicolumn{3}{|c|}{ Annual } & \multicolumn{3}{|c|}{ JJAS } & \multicolumn{3}{|c|}{$\mathrm{ON}$} & \multicolumn{3}{|c|}{ MAM } & \multicolumn{3}{|c|}{ DJF } \\
\hline & $d$ & $R$ & NSE & $d$ & $R$ & NSE & $d$ & $R$ & NSE & $d$ & $R$ & NSE & $d$ & $R$ & NSE \\
\hline \multicolumn{16}{|l|}{ Banjar } \\
\hline IMD1 & 0.64 & 0.46 & 0.07 & 0.69 & 0.53 & 0.03 & 0.92 & 0.86 & 0.69 & 0.81 & 0.68 & 0.41 & 0.69 & 0.51 & -0.56 \\
\hline $\mathrm{CRU}$ & 0.55 & 0.41 & 0.17 & 0.58 & 0.44 & -0.28 & 0.70 & 0.69 & 0.37 & 0.54 & 0.61 & -0.65 & 0.67 & 0.66 & 0.10 \\
\hline IMD. 25 & 0.89 & 0.87 & 0.72 & 0.88 & 0.82 & 0.66 & 0.99 & 0.98 & 0.95 & 0.97 & 0.95 & 0.90 & 0.95 & 0.93 & 0.83 \\
\hline \multicolumn{16}{|l|}{ Berinag } \\
\hline IMD1 & 0.51 & 0.39 & -0.68 & 0.47 & 0.20 & -0.76 & 0.90 & 0.83 & 0.55 & 0.64 & 0.50 & 0.12 & 0.88 & 0.81 & 0.65 \\
\hline CRU & 0.49 & 0.35 & -0.90 & 0.47 & 0.26 & -0.84 & 0.68 & 0.50 & 0.14 & 0.61 & 0.42 & 0.11 & 0.83 & 0.83 & 0.56 \\
\hline IMD. 25 & 0.75 & 0.63 & 0.17 & 0.73 & 0.57 & 0.11 & 0.93 & 0.89 & 0.79 & 0.88 & 0.78 & 0.60 & 0.91 & 0.87 & 0.73 \\
\hline \multicolumn{16}{|l|}{ Bironkhol } \\
\hline IMD1 & 0.62 & 0.47 & -0.43 & 0.57 & 0.47 & -1.17 & 0.93 & 0.88 & 0.74 & 0.71 & 0.55 & 0.29 & 0.73 & 0.62 & 0.35 \\
\hline CRU & 0.64 & 0.50 & 0.25 & 0.69 & 0.56 & 0.22 & 0.58 & 0.50 & 0.25 & 0.72 & 0.60 & 0.36 & 0.66 & 0.62 & 0.24 \\
\hline IMD. 25 & 0.94 & 0.90 & 0.80 & 0.90 & 0.84 & 0.68 & 0.99 & 0.99 & 0.98 & 0.86 & 0.78 & 0.47 & 0.96 & 0.95 & 0.88 \\
\hline \multicolumn{16}{|l|}{ Hamirpur } \\
\hline IMD1 & 0.96 & 0.95 & 0.85 & 0.96 & 0.93 & 0.86 & 0.99 & 0.99 & 0.97 & 0.99 & 0.98 & 0.95 & 0.98 & 0.96 & 0.92 \\
\hline $\mathrm{CRU}$ & 0.55 & 0.55 & -0.85 & 0.59 & 0.58 & -0.43 & 0.50 & 0.68 & 0.23 & 0.79 & 0.82 & 0.48 & 0.66 & 0.62 & -0.01 \\
\hline IMD. 25 & 0.78 & 0.66 & 0.11 & 0.80 & 0.67 & 0.29 & 0.97 & 0.96 & 0.90 & 0.93 & 0.88 & 0.74 & 0.90 & 0.82 & 0.67 \\
\hline \multicolumn{16}{|l|}{ Kasauli } \\
\hline IMD1 & 0.49 & 0.57 & -1.76 & 0.50 & 0.62 & -1.38 & 0.82 & 0.83 & 0.57 & 0.80 & 0.81 & 0.48 & 0.76 & 0.74 & 0.32 \\
\hline CRU & 0.49 & 0.62 & -1.46 & 0.52 & 0.60 & -0.97 & 0.47 & 0.68 & 0.14 & 0.69 & 0.76 & 0.26 & 0.65 & 0.66 & -0.02 \\
\hline IMD. 25 & 0.78 & 0.73 & 0.28 & 0.72 & 0.69 & 0.15 & 0.98 & 0.96 & 0.92 & 0.93 & 0.88 & 0.76 & 0.92 & 0.84 & 0.74 \\
\hline \multicolumn{16}{|l|}{ Kathgodam } \\
\hline IMD1 & 0.50 & 0.54 & -1.74 & 0.46 & 0.44 & -2.75 & 0.95 & 0.93 & 0.85 & 0.76 & 0.73 & 0.10 & 0.85 & 0.77 & 0.55 \\
\hline CRU & 0.50 & 0.47 & -1.57 & 0.48 & 0.43 & -2.09 & 0.68 & 0.57 & 0.32 & 0.78 & 0.72 & 0.38 & 0.75 & 0.70 & 0.42 \\
\hline IMD .25 & 0.75 & 0.85 & 0.22 & 0.68 & 0.77 & -0.17 & 0.98 & 0.97 & 0.94 & 0.90 & 0.90 & 0.64 & 0.94 & 0.91 & 0.79 \\
\hline \multicolumn{16}{|l|}{ Nurpur } \\
\hline IMD1 & 0.82 & 0.77 & 0.47 & 0.83 & 0.78 & 0.53 & 0.98 & 0.98 & 0.92 & 0.96 & 0.93 & 0.85 & 0.92 & 0.93 & 0.76 \\
\hline CRU & 0.45 & 0.48 & -2.18 & 0.49 & 0.51 & -1.44 & 0.36 & 0.55 & 0.14 & 0.77 & 0.81 & 0.45 & 0.60 & 0.73 & -0.21 \\
\hline IMD. 25 & 0.78 & 0.85 & -0.01 & 0.79 & 0.81 & 0.13 & 0.98 & 0.97 & 0.94 & 0.95 & 0.95 & 0.76 & 0.98 & 0.97 & 0.92 \\
\hline \multicolumn{16}{|l|}{ Rajpur } \\
\hline IMD1 & 0.44 & 0.71 & -3.92 & 0.45 & 0.54 & -2.87 & 0.80 & 0.73 & 0.50 & 0.53 & 0.58 & 0.17 & 0.82 & 0.83 & 0.45 \\
\hline $\mathrm{CRU}$ & 0.38 & 0.70 & -5.97 & 0.40 & 0.61 & -4.57 & 0.50 & 0.61 & 0.18 & 0.43 & 0.45 & 0.15 & 0.69 & 0.71 & 0.20 \\
\hline IMD. 25 & 0.70 & 0.83 & -0.33 & 0.70 & 0.80 & -0.23 & 0.91 & 0.87 & 0.75 & 0.71 & 0.62 & 0.38 & 0.93 & 0.86 & 0.75 \\
\hline \multicolumn{16}{|l|}{ Ranikhet } \\
\hline IMD1 & 0.85 & 0.73 & 0.48 & 0.80 & 0.64 & 0.30 & 0.95 & 0.92 & 0.75 & 0.85 & 0.74 & 0.54 & 0.89 & 0.80 & 0.62 \\
\hline $\mathrm{CRU}$ & 0.83 & 0.70 & 0.44 & 0.79 & 0.63 & 0.28 & 0.69 & 0.53 & 0.21 & 0.82 & 0.78 & 0.53 & 0.80 & 0.82 & 0.42 \\
\hline IMD. 25 & 0.92 & 0.86 & 0.70 & 0.91 & 0.84 & 0.67 & 0.96 & 0.95 & 0.82 & 0.93 & 0.88 & 0.78 & 0.96 & 0.93 & 0.87 \\
\hline
\end{tabular}

$d$ : $d$-index; $R$ : correlation coefficient.

Bold values: significant at $5 \%$.

negative for the annual (IMD1: -0.74 and CRU: - 1.34) and monsoon (IMD1: -0.80 and CRU: - 1.12) rainfall. A negative value of NSE represents the residual variance (described by the numerator in the expression of NSE in table 1), which is larger than the data variance (described by the denominator in the expression of NSE in table 1) (Xia et al. 2014), and hence the performance of IMD1 and CRU data is unacceptable for majority of stations. Rajpur was the only station which has shown the negative value of NSE for all the gridded datasets for annual and monsoon rainfall. The values of agreement indices were higher in post-monsoon $(\mathrm{ON})$ season followed by winter (DJF) and pre-monsoon (MAM). Based on the analysis of results obtained from all the agreement indices, it was observed that the IMD.25 data is much efficient as it is consistently showing positive and higher values for each of the agreement indices than the other two gridded data. 
Table 4. Values of different error indices calculated for different gridded datasets for different seasons and annual time scale.

\begin{tabular}{|c|c|c|c|c|c|c|c|c|c|c|}
\hline \multirow{2}{*}{$\begin{array}{l}\text { Interpolated } \\
\text { stations }\end{array}$} & \multicolumn{2}{|c|}{ Annual } & \multicolumn{2}{|c|}{ JJAS } & \multicolumn{2}{|c|}{$\mathrm{ON}$} & \multicolumn{2}{|c|}{ MAM } & \multicolumn{2}{|c|}{ DJF } \\
\hline & NT & NM & $\mathrm{NT}$ & NM & NT & $\mathrm{NM}$ & NT & $\mathrm{NM}$ & NT & NM \\
\hline \multicolumn{11}{|l|}{ Banjar } \\
\hline IMD1 & 0.96 & 0.70 & 0.98 & 0.70 & 0.55 & 0.40 & 0.76 & 0.60 & 1.24 & 0.80 \\
\hline $\mathrm{CRU}$ & 0.91 & 0.60 & 1.12 & 0.90 & 0.79 & 0.50 & 1.28 & 1.10 & 0.95 & 0.80 \\
\hline IMD. 25 & 0.53 & 0.30 & 0.58 & 0.40 & 0.22 & 0.10 & 0.32 & 0.20 & 0.40 & 0.20 \\
\hline \multicolumn{11}{|l|}{ Berinag } \\
\hline IMD1 & 1.29 & 1.10 & 1.32 & 1.10 & 0.66 & 0.40 & 0.93 & 0.70 & 0.59 & 0.50 \\
\hline $\mathrm{CRU}$ & 1.37 & 1.20 & 1.35 & 1.10 & 0.92 & 0.60 & 0.94 & 0.70 & 0.66 & 0.50 \\
\hline IMD. 25 & 0.90 & 0.70 & 0.94 & 0.70 & 0.46 & 0.30 & 0.63 & 0.40 & 0.52 & 0.40 \\
\hline \multicolumn{11}{|l|}{ Bironkhol } \\
\hline IMD1 & 1.19 & 0.90 & 1.47 & 1.10 & 0.50 & 0.30 & 0.84 & 0.60 & 0.80 & 0.50 \\
\hline $\mathrm{CRU}$ & 0.86 & 0.60 & 0.88 & 0.60 & 0.86 & 0.40 & 0.79 & 0.60 & 0.87 & 0.60 \\
\hline IMD. 25 & 0.45 & 0.30 & 0.56 & 0.40 & 0.15 & 0.10 & 0.72 & 0.40 & 0.34 & 0.20 \\
\hline \multicolumn{11}{|l|}{ Hamirpur } \\
\hline IMD1 & 0.39 & 0.30 & 0.38 & 0.30 & 0.17 & 0.10 & 0.23 & 0.20 & 0.27 & 0.20 \\
\hline $\mathrm{CRU}$ & 1.35 & 1.10 & 1.19 & 1.00 & 0.87 & 0.40 & 0.71 & 0.50 & 1.00 & 0.70 \\
\hline IMD. 25 & 0.94 & 0.80 & 0.84 & 0.70 & 0.32 & 0.20 & 0.50 & 0.40 & 0.57 & 0.40 \\
\hline \multicolumn{11}{|l|}{ Kasauli } \\
\hline IMD1 & 1.65 & 1.50 & 1.53 & 1.40 & 0.65 & 0.30 & 0.71 & 0.50 & 0.82 & 0.60 \\
\hline CRU & 1.56 & 1.40 & 1.40 & 1.20 & 0.92 & 0.40 & 0.85 & 0.60 & 1.00 & 0.80 \\
\hline IMD. 25 & 0.84 & 0.60 & 0.92 & 0.70 & 0.29 & 0.20 & 0.48 & 0.30 & 0.51 & 0.40 \\
\hline \multicolumn{11}{|l|}{ Kathgodam } \\
\hline IMD1 & 1.64 & 1.50 & 1.92 & 1.80 & 0.39 & 0.20 & 0.94 & 0.80 & 0.67 & 0.50 \\
\hline $\mathrm{CRU}$ & 1.59 & 1.40 & 1.74 & 1.60 & 0.82 & 0.40 & 0.78 & 0.60 & 0.75 & 0.50 \\
\hline IMD. 25 & 0.88 & 0.80 & 1.07 & 0.90 & 0.25 & 0.20 & 0.60 & 0.50 & 0.45 & 0.30 \\
\hline \multicolumn{11}{|l|}{ Nurpur } \\
\hline IMD1 & 0.72 & 0.50 & 0.68 & 0.40 & 0.27 & 0.10 & 0.39 & 0.30 & 0.49 & 0.40 \\
\hline CRU & 1.77 & 1.60 & 1.55 & 1.30 & 0.92 & 0.40 & 0.74 & 0.60 & 1.09 & 0.80 \\
\hline IMD. 25 & 1.00 & 0.90 & 0.93 & 0.80 & 0.25 & 0.20 & 0.49 & 0.40 & 0.29 & 0.20 \\
\hline \multicolumn{11}{|l|}{ Rajpur } \\
\hline IMD1 & 2.20 & 2.10 & 1.95 & 1.80 & 0.70 & 0.30 & 0.91 & 0.50 & 0.74 & 0.60 \\
\hline $\mathrm{CRU}$ & 2.62 & 2.50 & 2.34 & 2.20 & 0.90 & 0.40 & 0.91 & 0.40 & 0.89 & 0.60 \\
\hline IMD. 25 & 1.14 & 1.00 & 1.10 & 1.00 & 0.50 & 0.20 & 0.78 & 0.40 & 0.50 & 0.40 \\
\hline \multicolumn{11}{|l|}{ Ranikhet } \\
\hline IMD1 & 0.72 & 0.60 & 0.83 & 0.60 & 0.50 & 0.30 & 0.68 & 0.40 & 0.61 & 0.50 \\
\hline $\mathrm{CRU}$ & 0.74 & 0.60 & 0.84 & 0.60 & 0.89 & 0.50 & 0.68 & 0.40 & 0.76 & 0.60 \\
\hline IMD. 25 & 0.55 & 0.40 & 0.57 & 0.40 & 0.42 & 0.20 & 0.47 & 0.30 & 0.36 & 0.30 \\
\hline
\end{tabular}

NT: NTRMSE; NM: NMAE.

\subsubsection{Analysis of error statistics}

Table 4 shows the calculated values of two error indices, i.e., NTRMSE and NMAE, for different gridded dataset in a different season. The mean values of NTRMSE and NMAE of IMD.25 data for annual, monsoon, post-monsoon, pre-monsoon and winter were $(0.80,0.64),(0.83,0.67),(0.32$, $0.19),(0.55,0.37)$ and $(0.44,0.31)$, respectively. Similarly, for IMD1 data, they were calculated as $(1.20,1.02),(1.23,1.02),(0.49,0.27),(0.71,0.51)$ and $(0.69,0.51)$, respectively. It was found that the calculated values of both the error indices were low for IMD.25 data, whereas they were high for CRU data. For CRU data the mean values of NTRMSE and NMAE for annual, monsoon, post-monsoon, pre-monsoon and winter were $(1.42,1.22),(1.38$, $1.17),(0.88,0.44),(0.85,0.61)$, and $(0.89,0.66)$, respectively. The mean values of error indices of all the datasets were low for post-monsoon rainfall whereas they were high for monsoon rainfall. A higher value of NTRMSE of IMD1 and CRU data implies that the residual variance of these datasets was higher as compared to the IMD.25 data. Some stations such as Kasauli, Kathgodam and Rajpur have shown very high values of error 


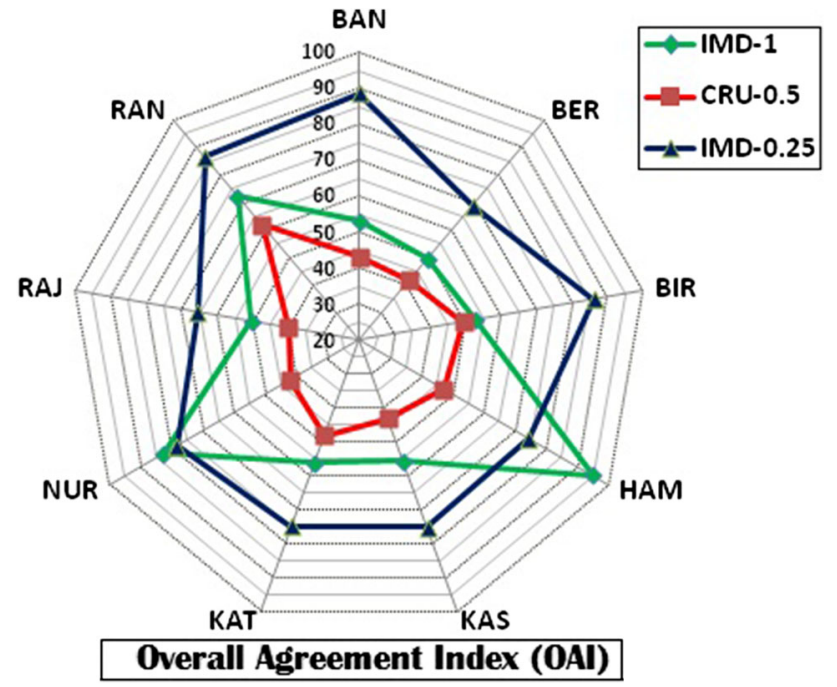

Figure 7. OAI (\%) developed from the $R, d$-index and NSE for each rain-gauge station.

indices for IMD1 and CRU data, which was almost $\sim 60 \%$ more than the IMD. 25 data.

Hence, unlike different agreement indices, the analysis of error indices also reflects the IMD. 25 data can be used as an efficient source of data to fill the missing values in the observational data.

\subsection{Analysis of $O A I$}

Figure 7 shows the calculated values of OAI (in percentage) developed from the $R, d$-index, and NSE for each rain-gauge station. Here, a simple example of the calculation of OAI has been presented for the Banjar station, for a better understanding of the readers. From table 3, calculating the total sum of all the agreement indices (excluding the negative values) at all seasons gives 7.99, 6.49 and 13.29 for IMD1, CRU and IMD.25 gridded data, respectively. In an ideal condition, the total sum of all the agreement indices for all the season is 15. Hence, for the Banjar station, the OAI value is $53 \%, 43 \%$ and $89 \%$ for the IMD1, CRU and IMD. 25 data, respectively. The results obtained from all the stations are displayed in figure 7 .

Based on the values of OAI in figure 7 , it was noticed that for IMD.25 data, the calculated values of OAI were greater than $\sim 80 \%$ for the majority of the stations indicating its superior performance over the other two datasets. The OAI value for the IMD1 data was very high $(>90 \%)$ for two stations namely Hamirpur and Nurpur. The OAI values calculated for the global observational gridded data, i.e., $\mathrm{CRU}$, showed that they were very low $(<60 \%)$ for all stations indicating their poor performance over the WHR and may not be considered in the missing values replacement techniques. Figure 7 also reflected that gridded data prepared for a target country where missing values need to be replaced is more appropriate and reliable to be used compared to global observation gridded data sources.

\section{Conclusion}

The present study has been carried out to select a suitable gridded data from a list of three potential gridded rainfall data sources, viz., IMD $1^{\circ} \times 1^{\circ}$ gridded data, IMD $0.25^{\circ} \times 0.25^{\circ}$ gridded data and CRU TS v. $3.210 .5^{\circ} \times 0.5^{\circ}$ gridded data to substitute a huge number of missing values in the monthly rain-gauge data procured from IMD for the WHR. The performances of each of the data sources were quantitatively tested through the calculation of different agreement indices, error indices and an OAI. The study has been concluded with the following major findings:

1. The IMD.25 interpolated station characterised by a very high value of linear correlation coefficient, and different agreement indices and less value of error indices.

2. OAI for the IMD.25 interpolated data was very high than the IMD1 and the CRU data. Hence, they can be used as an effective data source for substituting missing values in the rain-gauge data over the WHR for any long-term climate change study. IMD1 data may also be used to substitute missing values in some specific stations after a proper comparison with IMD.25 data over the WHR as well as any other region of study in India.

3. In the process of missing value substitution, local gridded information of the concerned country may be used more confidently and reliably compared to global scale available gridded information like CRU.

The techniques used in the present study may be tested over different regions of India to generate a complete long-term dataset for climate change analysis with minimum error.

\section{Acknowledgements}

The authors would like to acknowledge the Norway Research Council and Norwegian Water Resources and Energy Directorate for their funding assistance 
through the Indo-Norway international research project 'INDICE'. The National Climate Centre (NCC) of Indian Meteorological Department (IMD), Pune and Climate Research Unit (CRU), UK, are also acknowledged for making data available for this study. The help provided by Dr D S Pai, IMD, in the course of this work is also acknowledged. The constructive suggestions provided by two anonymous reviewers to improve the quality of the paper have been highly appreciated.

\section{References}

Azid A, Juahir H and Latif M T et al. 2013 Feed-forward artificial neural network model for air pollutant index prediction in the southern region of peninsular Malaysia; $J$. Environ. Protect. 04 1-10, https://doi.org/10.4236/jep. 2013.412a001

Benestad R E, Mezghani A and Parding K M 2014 ESD for Mac \& Linux/ESD for Windows; version 17. figshare, http://figshare.com/articles/esd_for_Mac_amp_ Linux/1160493.

Bothale R V, Rao P V N, Dutt C B S and Dadhwal V K 2015 Detection of snow melt and freezing in Himalaya using OSCAT data; J. Earth Syst. Sci. 124(1) 101-113.

Castaneda M and Gonzalez M 2008 Statistical analysis of precipitation trends in the Patagonia region in southern South America; Atmósfera 21(3) 303-317.

Chang K 2013 Introduction to geographic information systems (7th edn), McGraw-Hill, New York.

Covey C, AchutaRao K M, Fiorino M, Gleckler P T, Taylor K E and Wehner M F 2002 Intercomparison of climate datasets as a measure of observational uncertainty; Program for Climate Model Diagnosis and Intercomparison, UCRL-ID-147371, Lawrence Livermore National Laboratory, Livermore, CA.

Das L and Lohar D 2005 Construction of climate change scenarios for a tropical monsoon region; Clim. Res. 30 39-52.

Das L, Annan J D, Hargreaves J C and Emori S 2012 Improvements over three generations of climate model simulations for eastern India; Clim. Res. 51(3) 201-216.

Das L, Meher J K, Akhter J, Benestad R E and Mezghani A 2014 Assessing the performance of CMIP5 GCMs in simulating the observed annual and seasonal rainfall over the Western Himalayan Region of India; J. Agrometeorol. Spec. Issue 16 139-142.

Das L, Meher J K and Dutta M 2016 Construction of rainfall change scenarios over the Chilka Lagoon in India; Atmos. Res. 182 36-45, https://doi.org/10.1016/j.atmosres.2016. 07.013

Das L, Dutta M, Mezghani A and Benestad R E 2017 Use of observed temperature statistics in ranking CMIP5 model performance over the Western Himalayan Region of India; Int. J. Climatol., https://doi.org/10.1002/joc.5193.

Dimri A P 2012 Atmospheric water budget over the western Himalayas in a regional climate model; J. Earth Syst. Sci. 121(4) 963-973.
Dimri A P, Yasunari T, Kotlia B S, Mohanty U C and Sikka D R 2016 Indian winter monsoon: Present and past; Earth-Sci. Rev. 163 297-322, https://doi.org/10. 1016/j.earscirev.2016.10.008.

Dominick D, Juahir H and Latif M T et al. 2012 Spatial assessment of air quality patterns in Malaysia using multivariate analysis; Atmos. Environ. 60 172-181, https:// doi.org/10.1016/j.atmosenv.2012.06.021.

Geyer C J 1999 Likelihood inference for spatial point processes; In: Stochastic geometry: Likelihood and computation (eds) Barndorff-Nielsen O E, Kendall W S and van Lieshout M N M, Chapman \& Hall/CRC, Boca Raton, FL, pp. 79-140.

Geyer C J and Thompson E A 1992 Constrained Monte Carlo maximum likelihood for dependent data (with discussion); J. R. Stat. Soc. Ser. B 54 657-699.

Geyer C J and Thompson E A 1995 Annealing Markov chain Monte Carlo with applications to ancestral inference; J. Am. Stat. Assoc. 90 909, https://doi.org/10. $2307 / 229132$.

Janssen P H M and Heuberger P S C 1995 Calibration of process-oriented models; Ecol. Model. 83(1-2) 55-66.

Joshi J C and Ganju A 2010 Use of objective analysis to estimate winter temperature and precipitation at different stations over western Himalaya; J. Earth Syst. Sci. 119(5) 597-602.

Joshi V and Negi G C S 1995 Analysis of longterm weather data from Garhwal Himalaya; ENVIS bulletin on Himalayan ecology, Kosi, Almora, India; GBPIHE\&D 3(1-2) 63-64.

Junninen H, Niska H and Tuppurainen K et al. 2004 Methods for imputation of missing values in air quality datasets; Atmos. Environ. 38 2895-2907, https://doi.org/10.1016/ j.atmosenv.2004.02.026.

Legates D R and McCabe Jr G J 1999 Evaluating the use of "Goodness-of-Fit" measures in hydrologic and hydroclimatic model validation; Water Resour. Res. 35(1) 233-241.

Palutikof J P, Winkler J A, Goodess C M and Andresen J A 1997 The simulation of daily temperature time series from GCM output. I. Comparison of model data with observations; J. Clim. 10 2497-2513.

Peng L L L 2005 A review of missing data treatment methods; Int. J. Intel. Inf. Manag. Syst. Tech. 1(3).

Meher J K, Das L and Akhter J 2014 Future rainfall change scenarios simulated through AR4 and AR5 GCMs over the Western Himalayan Region; J. Agrometeorol. Spec. Issue 16 53-58

Meher J K, Das L and Singh V J 2015 Analysis of trends in monsoon rainfall and its influence on productivity of Kharif rice: A district wise latest update; In: Crop productivity and plant disease management (eds) Chauhan A, Bharti P K and Sadana D, Discovery Publications, ENV Discovery Publications, ENV Books series, New Delhi, India, pp. 60-77.

Meher J K, Das L, Akhter J, Benestad R E and Mezghani A 2017a Performance of CMIP3 and CMIP5 GCMs to simulate observed rainfall characteristics over the Western Himalayan region; J. Climate, https://doi.org/10.1175/ JCLI-D-16-0774.1.

Meher J K, Das L, Benestad R E and Mezghani A 2017b Analysis of winter rainfall change statistics over the 
Western Himalaya: The influence of internal variability and topography. Int. J. Climatol., https://doi.org/10. 1002/joc.5385.

Mir R A, Jain S K, Saraf A K and Goswami A 2015 Decline in snowfall in response to temperature in Satlej basin, western Himalaya; J. Earth Syst. Sci. 124(2) 365382.

Nash J E and Sutcliffe J V 1970 River flow forecasting through conceptual models parts I - A discussion of principles; J. Hydrol. 10(3) 282-290.

Pai D S, Sridhar L, Rajeevan M, Sreejith O P, Satbhai N S and Mukhopadhyay B 2014 Development of a new high spatial resolution $(0.25 \times 0.25)$ long period (1901-2010) daily gridded rainfall dataset over India and its comparison with existing datasets over the region; Mausam 65(1) $1-18$.

Rajeevan M, Bhate J and Jaswa A K 2008 Analysis of variability and trends of extreme rainfall events over India using 104 years of gridded daily rainfall data; J. Geophys. Res. 35 L18707.

Rao K S 1997 Natural resource management and development in Himalaya: A recourse to issues and strategies; ENVIS Monograph 1, EICHE, GBPIHE\&D, Kosi, Almora, India.

Sahu S 2014 Design and implementation of a heterogeneous sensor-based embedded system for flood management; Doctoral dissertation, Department of Electronics and Communication Engineering, NIT Rourkela, India.
Shrestha M L 2000 Interannual variation of summer monsoon rainfall over Nepal and its relation to southern oscillation index; J. Meteor. Atmos. Phys. 75 21-28.

Singh P and Kumar N 1997 Effect of orography on precipitation in the western Himalayan region; $J$. Hydrol. 199 183-206.

Taylor K E 2001 Summarizing multiple aspects of model performance in a single diagram; J. Geophys. Res. 106 7183-7192.

Willmott C J 1981 On the validation of models; Phys. Geogr. 2 184-194.

Willmott C J 1982 Some comments on the evaluation of model performance; Bull. Am. Meteor. Soc. 63 13091313.

Xia Y, Ek M B, Peters-Lidard C D, Mocko D, Svoboda M, Sheffield J and Wood E F 2014 Application of USDM statistics in NLDAS-2: Optimal blended NLDAS drought index over the continental United States; J. Geophys. Res. Atmos. 119(6) 2947-2965.

Xie P and Arkin P A 1995 An intercomparison of gauge observations and satellite estimates of monthly precipitations; J. Appl. Meteor. 34 1143-1159.

Yilmaz K K and Hogue T S 2005 Intercomparison of rain gauge, radar, and satellite based precipitation estimates with emphasis on hydrologic forecasting; J. Hydrometeor. 6 497-517.

Zambrano-Bigiarini M 2014 hydroGOF: Goodness-of-fit functions for comparison of simulated and observed hydrological time series; $\mathrm{R}$ package version $0.3-8$. 